\title{
Change Management In Current Secondary Schools In Vietnam (Case Of Ly Thanh Tong Secondary School, District 8, Ho Chi Minh City)
}

\author{
Nguyen Long Giao \\ Rector, Secondary school Ly Thanh Tong - Postgraduate at University of Social \\ Sciences and Humanities, Vietnam National University Ho Chi Minh City \\ E-mail: longgiaotphcm@gmail.com
}

\section{Summary:}

Currently, due to the impact of the scientific and technological revolution; besides the fourth industrial revolution, education in general and lower secondary education in Vietnam in specific has been changing and transforming in order to adapt to the new age. Educational management and school management play a directional role, which is one of the breakthroughs and decisive factors to the quality and effectiveness of education. And with the comprehensive and all-round impact of the fourth industrial revolution, the trend in change management in middle schools tends to be changed so as to compete on quality and efficiency to meet the increasing needs of learners as well as the increasingly strict requirements of society. By using a group of theoretical research methods and a group of practical research methods, this article focuses on analyzing and clarifying the content of the change management process in schools and the role of principals in school management of Vietnam's secondary schools, which is shown through the process of leading the renewal of teaching activities at Ly Thanh Tong secondary school, District 8, Ho Chi Minh City. The study also shows the content of change management, the change management process in the school, the principal's roles in change management in the unit as well as the relationship in the leadership process, as evidenced by the teaching activities at Ly Thanh Tong secondary school, District 8, Ho Chi Minh City.

Key words:

Management, change management, education, secondary education, Ho Chi Minh city, Viet Nam.

\section{Introduction}

In the past 35 years of implementing the innovation, Vietnam has achieved great achievements which have historical significance, strong and comprehensive development. Due to the difficult context caused by the Covid-19 pandemic, it has created new requirements and generated rapid and profound changes to all fields of global social activities, including education. It affects from new requirements for global socio-economic development to new requirements for global citizen personality model, and continuously to new requirements for the quality and 
effectiveness of education. Educational management and school management play a directional role, which is one of the breakthroughs and decisive factors to the quality and effectiveness of education. Therefore, the reform of leadership and educational management in general and secondary schools, in particular, is an objective necessity and also an urgent requirement of society during the current period, especially before the impact and influence of science and technology, and the fourth industrial revolution (Industry 4.0).

\section{Research questions}

Question 1: What contents does the change management process of schools include?

Question 2: What is the role of the principal in change management in secondary schools in Vietnam nowadays?

\section{Research purposes}

The purpose of the article is to analyze and clarify the content of the change management process in schools and the role of principals in it at secondary schools in Vietnam today, as evidenced by the process of directing the renovation of teaching activities at Ly Thanh Tong junior high school, District 8, Ho Chi Minh City.

\section{Research methods}

- Group of theoretical research methods: using analysis, synthesis, and theoretical systematization to define concepts of toolkits and set up a theoretical layout for the paper

- Group of practical research methods:

+ Pedagogic observation method: observing the activities of administrators, teachers, and students in school so as to evaluate the changing state in secondary schools.

+ In-depth interview method: collecting opinions of administrators, educators, teachers, and students to examine the reality of change management in secondary schools.

In addition, the article also combines other research methods such as deduction and induction, logic and history, comparison and contrast between theory and practice.

\section{Research overview}

Change management topic in education has many authors be attracted to do research at many aspects related to leadership and management, besides leadership and management styles, the qualities and abilities of a leader, a manager. According to the theory of transformational leadership, Burns (1977) showed that we can separate leaders into two types, transactional leaders and transformational leaders. The first type of leaders treats their followers in a practical way through communication. The other type of leaders who are visionary leaders, want to find in 
their followers better natures and have them reach higher and more general levels of need and purpose. In other words, according to this model, the leader is supposed to be the main factor that helps change. According to Fayol (1949), Administration is an activity that each organization (families, business, government) has, which includes 5 functions: plan, organization, command, coordination, and control. The administration is exactly deploying a plan, organising, commanding, coordinating, and controlling the process of implementing the plan. As said by Peter F. Drucker (1969), after all, management is practice. Its essence isn't based on the perception but the action; its verification is not in logic but in results, and; its unique power is achievements.

Besides, discussing change management is also concerned and studied by researchers and managers. In the book "Change Management", published by Ho Chi Minh General Publishing House, 2006, R.Heller had researched and pointed out the urgency of school change, the steps to implement it, and a successful school model. A.Bruce and K.Langdon (2005): "Project management", published by Ho Chi Minh General Publishing House; NIE (Singapore) (2008): Leaders In Education Programme International; CY Charney (2007): "Instant Manager"- Tri Thuc Publishing House. Đang Xuan Hai (2005) "Applying the theory of Change Management to guide the innovation of teaching methods in universities in the current period", posted on Education Magazine No.3.

\section{Research results}

\section{Change management and change management process in schools}

Currently, education and training are running towards quality assurance, autonomous schools and change management. This has reflected the necessity of innovation in education and training in the globalization period of the economysociety, as well as science and technology. And with the comprehensive and allround impact of the fourth industrial revolution, the trend in change management in middle schools tends to be changed so as to compete on quality and efficiency to meet the increasing needs of learners as well as the increasingly strict requirements of society.

Change management in schools is managing the changes happening in schools due to various reasons such as the directions from different levels of managers, the needs and demands of students' parents, the requirements coming from the local socio-economic development background, or school administrators and pedagogical staff's needs. The content of Change management in schools associates with the practical conditions of the lower secondary schools which the schools need to implement, including some basic contents related to Change Management in Human Resources; Change Management in Finance; Change Management in Professional Knowledge; and Change Management in Learners. (shown in details as below) 
Firstly, Change Management in Human Resources: Because of job's requirements and the reality, school's administrators, teachers, and staff need to have changes in quantity, qualification (ability, quality); structure (department joining and separating, age, gender, academic level)

Secondly, Change Management in Finance for school activities: Financial sources can be from the government budget, school's legitimate income, and other funding sources. Therefore, the level of financial investment for the school activities can also be changed to suit the actual situation and ensure that the activities have the best quality and are effective.

Thirdly, Change Management in Facilities, Vehicles, and Equipment: The investment for those things can be able to be changed to adapt to the given budget and the school activities' requirements.

Fourthly, Change Management in Professional Knowledge: Changes in education and teaching are implemented to meet the requirements of educational innovation in the new context. These changes, through a system of legal documents, are directly instructed by the administrators of the Ministry of Education and Training; Departments; as well as Education and Training Departments. This content is also related to other aspects such as the content of the educational and teaching programs, educational and teaching methods, examine, and evaluate the results of education and teaching.

Finally, Change Management in Learners: In the competitive period of educational institutions and the innovation trend tending to increase schools' autonomy, the change in the number of students is a content that needs actively receiving and managing. In Viet Nam, applying the Golden population structure, mainly in Ho Chi Minh City, has some influence on students' qualifications in terms of physicality, comprehension, degree, and ability. These changes have to be seen to calculate the school admission criteria, to prepare for training programs, and to ensure the output standard of the school.

At present, many countries in the world strictly focus on the leadership role of the school principals and pay attention to how to lead change in schools. Leadership and change management is a process that builds a bridge between visions and actions. Generally, the change management process consists of four steps.

Step 1, preparing for change. At this step, the administrator determines and points out things to do that are necessary to change the secondary school. The school administrator must identify the characteristics, features, and the need-solving basic issues of "the change" that needs to be managed. The administrator has to analyze the school's ability to accept changes, forecast trends, opportunities, risks, and the process of change in school to deal with the given challenges. 
Step 2, building a change plan. At this step, it is important to understand the purposes, issues, changes, so that unnecessary interference can be avoided. Planning to implement the target system means finding resources (human, materials, financial sources), time, and space needed to achieve the goals. Expenditures must be determined; moreover, finding the lowest cost options while realising each goal is a must-done. Planned change is a kind of organizational change that is the most commonly used nowadays.

Step 3, implementing change. Making drafts and decisions related to the change of the school, are things to do at this step. They consist of identifying and categorizing the activities needed to achieve the goals; optimally grouping activities according to the human and available resources based on the situation to form the organizational structure; selecting and using suitable staff to implement changes; assigning responsibilities and delegating authority to departments; and binding departments vertically and horizontally in the system of responsibility, authority, and information.

Step 4, examining, evaluating the implementation of the change, and reinforcing the change. At this step, schools need to monitor the progress, maintain the balance, review the results, successes, and failures to adjust goals and plans. At the same time, it is necessary to verify and evaluate the results, the quality and the school's capacity of change.

\section{The principal's role in change management at the unit}

The principal of a secondary school is the leader and the manager of the school, who is the key to the changing as well as managing. As a result, activities run stably in order to achieve goals and serve the school's sustainable development. In general, the role of the principal in change management at the unit is demonstrated in the following aspects:

Firstly, leadership and change management in secondary schools

Providing a various and diverse curriculum is a primary goal that principals take it as a priority. They also need to pay more attention to higher-order cognition as well as lower-order cognition, ensure a productive and helpful learning environment. Creating a positive working atmosphere, a clear organizational trait, characterized by missions, values, goals, and performance standards is another must-done of the principals, along with taking work as a center, creating an open, friendly, and culturally interesting workplace.

Secondly, school culture

It must be understood that school culture is a set of a school's characteristics including standards, values, beliefs, and behaviors, which makes school culture different from other organizations. School culture is related to the entire material and spiritual life of a school. It demonstrates first in the visions, missions, philosophy, goals, values, leadership style, and management. Behaving according to 
standards, values, beliefs, codes of conduct, etc. is considered to be good and accepted by everyone in the school. Therefore, the role of the principal in leading the development of school culture is significant because the principal has a decisive role in managing the development of school culture.

Thirdly, strategic plan for school development

It is necessary to understand that a strategic plan is a plan in which there are major directions, shows the actual images of the future that the school hopes to achieve and strategic solutions to get on the basis of current capabilities. It ensures that the school has outstanding development. In planning, it is also essential to be aware of and understand concepts related to the mission affirming the purpose, the reasons for the school's existence, priority service areas, and service manner that will be implemented to satisfy students' educational needs; the values which the school commits to its stakeholders, the principles that guide the behavior of its members; a vision-an idea of which the school can achieve in the future, expressing the wishes of the school and the community.

Fourthly, development of the school staff

It must be acknowledged that the official cadres and officers are the basic forces participating in the construction and development of the school; among them, the teaching staff plays a decisive role in the school's educational quality. Therefore, when building teams, the principal needs to build teams of teachers and educational administrators which are standardised, well-qualified, sufficient in quantity and synchronous in structure, and especially pays attention to improve professional skills and career to adapt to the change of the fourth industrial revolution.

\section{As evidenced by the process of directing the renewal of teaching activities at Ly Thanh Tong secondary school, District 8, Ho Chi Minh City}

Ly Thanh Tong secondary school, District 8, was established as stated by Decision No: 4273/QĐ -UBND 09/07/2013 of the People's Committee of District 8. As of August 2021, the school has 66 official cadres, teachers, officers and employees, with $100 \%$ of teachers and staff meeting the standards (of which, Ph.D. and Master degrees accounting for 15.87\%). The school has 36 classes, with 585 male students and 639 female students. It is implementing an advanced - modern model which reached national standards level 2, and achieved educational quality accreditation level 3. The construction scale includes a 4-storey classroom block (01 ground floor, 03 floors), a sports block, a teacher's garage, a security house, and a transformer station. Designed system capacity contains 42 classrooms, 3 labs, which is capable of nearly 2000 students. In the coming period, the school will continue to innovate professional activities in the direction of studying lessons, innovating in testing and evaluation, continuously renewing teaching methods, 
developing the quality of human resources, investing in new appliances and equipment to keep being worthy as a national standard school.

Table of student types of the school, 2020-2021

\begin{tabular}{|c|c|c|c|c|c|c|c|c|c|c|c|c|}
\hline \multirow{3}{*}{ 苞 } & \multicolumn{3}{|c|}{ Grade 6} & \multicolumn{3}{|c|}{ Grade 7} & \multicolumn{3}{|c|}{ Grade 8} & \multicolumn{3}{|c|}{ Grade 9} \\
\hline & \multirow{2}{*}{$\begin{array}{l}\text { Numbe } \\
\text { r of } \\
\text { classes }\end{array}$} & \multicolumn{2}{|c|}{$\begin{array}{c}\text { Number } \\
\text { of } \\
\text { students }\end{array}$} & \multirow{2}{*}{$\begin{array}{l}\text { Numbe } \\
\mathrm{r} \text { of } \\
\text { classes }\end{array}$} & \multicolumn{2}{|c|}{$\begin{array}{c}\text { Number } \\
\text { of } \\
\text { students }\end{array}$} & \multirow{2}{*}{$\begin{array}{c}\text { Numbe } \\
\mathrm{r} \text { of } \\
\text { classes }\end{array}$} & \multicolumn{2}{|c|}{$\begin{array}{c}\text { Number of } \\
\text { students }\end{array}$} & \multirow{2}{*}{$\begin{array}{c}\text { Numbe } \\
\text { r of } \\
\text { classes }\end{array}$} & \multicolumn{2}{|c|}{$\begin{array}{c}\text { Number } \\
\text { of } \\
\text { students }\end{array}$} \\
\hline & & Sum & Girl & & Sum & Girl & & $\mathrm{Su}$ & $\begin{array}{c}\text { Gir } \\
1\end{array}$ & & $\begin{array}{c}\mathrm{Su} \\
\mathrm{m}\end{array}$ & $\begin{array}{c}\text { Gir } \\
1\end{array}$ \\
\hline $\begin{array}{l}\mathbf{0 t} \\
1\end{array}$ & 8 & $\begin{array}{c}27 \\
5\end{array}$ & $\begin{array}{c}14 \\
6\end{array}$ & 9 & $\begin{array}{c}30 \\
2\end{array}$ & $\begin{array}{c}15 \\
7\end{array}$ & 9 & 290 & 153 & 10 & 315 & 167 \\
\hline
\end{tabular}

Source: Final Report, Ly Thanh Tong secondary school, 2020-2021

Table of students' quality and achievement, 2020-2021

\begin{tabular}{|c|c|c|c|}
\hline Aspects & Classification & $\begin{array}{c}\text { School year results } \\
2020-2021\end{array}$ & $\begin{array}{c}\text { Striving targets } \\
2021-2022\end{array}$ \\
\hline \multirow{3}{*}{ Capacity } & Very good & $76.31 \%$ & $80 \%$ \\
\hline & Good & $21.83 \%$ & $20 \%$ \\
\hline & Average & $1.86 \%$ & $0 \%$ \\
\hline \multirow{3}{*}{ Conduct } & Very good & $96.79 \%$ & $100 \%$ \\
\hline & good & $3.21 \%$ & 0 \\
\hline & Average & 0 & 0 \\
\hline \multirow[t]{2}{*}{$\begin{array}{c}\text { Excellent } \\
\text { students and } \\
\text { Olympics }\end{array}$} & District stage & $\begin{array}{l}20 \text { students grade } 9 \text { (Grade } \\
6,7,8 \text { has no students since } \\
\text { the county doesn't hold } \\
\text { examination due to Covid- } \\
\text { 19.) }\end{array}$ & 100 \\
\hline & City stage & 25 & 30 \\
\hline Pass & & $100 \%$ & $100 \%$ \\
\hline
\end{tabular}

Source: Final Report, Ly Thanh Tong secondary school, 2020-2021

While the social context is currently changing, improving the quality of teaching is still the most urgent requirement and task of Ly Thanh Tong Secondary School that needs to be achieved. Therefore, managing teaching activities at Ly Thanh Tong Secondary School also needs attention, especially the renewal of the school management mechanism in the direction of democratization, socialization, the school's autonomy; and to be monitored and responsible for the explaination. When managing and directing the renovation of teaching activities at Ly Thanh Tong Secondary School, it is necessary to apply the knowledge of change management. These basic steps should be followed: 
Step 1: Preparing for change

The school's strengths, weaknesses, opportunities, and challenges in the innovation of teaching activities are necessarily identified by analyzing the school's situation. It is required to compare with the requirements of teaching innovation in the Master Program to identify the changes that the school needs to aim for, as well as, to research the quantity and the quality of the school's staff and teachers; teaching facilities and equipment; the school state, and the teachers' habits and inertia towards teaching activities. Furthermore, advantages and disadvantages are essentially determined when implementing the policy of innovating teaching content and methods. At the same time, it is necessary to accept the opinions and aspirations of everyone (including students and parents) about the desire to change seriously and understandingly.

Step 2: Building a change plan

In this step, it is necessary to develop a flexible teaching plan for the school while still ensure the program requirements. At the same time, it has to clearly define the objectives of innovation in school teaching activities. The process of making and implementing a plan to innovate teaching activities should be carried out according to the gradual renewal plan, implemented slowly but surely, sticked to focal point and main point. Principal, professional vice-principal and experts actively perform their roles in the process of directing and renovating school teaching activities. In addition, it is also necessary to focus on building a solution system in order to renew teaching activities and a roadmap so as to apply solutions.

Step 3: Implementing change

The implementing change process needs to find factors that encourage and support change: Find typical examples of enthusiastic participants in changing teaching methods, and organize teaching activities in schools to encourage participating in the movement. Create conditions for teachers having good achievements or being dedicated to finding new changes in teaching methods, to go on study tours at higher quality schools; have teachers trained according to the projects' program as well. Guide and tightly direct, specifically require each teacher who is involved in changing teaching activities to work towards executing new programs. Punctually and objectively assess the implementation of the contents and targets set out for each activity; provide and support resource conditions; encourage by spiritual or material reward or both; create conditions for teachers to deploy, replicate and maintain innovation. Implementing the system of identified solutions and building emulation movements to innovate teaching and learning activities are also a matter that need to be concerned and focused on in this third step.

Step 4: Examining, evaluating the implementation of the change, and reinforcing the change 
Schools need to assess the change in the awareness of the teaching innovation issue, as well as analyze, evaluate and learn from experience to be able to plan and innovate teaching activities in the coming school years. It is necessary to closely direct and create favorable conditions for teachers to continue to make differences in teaching activities. Teaching innovation is included in the action plans of schools, professional groups and teachers.

\section{Basic solutions in Change Management at Ly Thanh Tong secondary school, District 8, Ho Chi Minh City in the current period \\ First, focus on managing changes}

Industry 4.0 has had strong and swift impacts on society-economy. In fact, the "confrontation" between the two principles "non-prohibited law" and "permissive law" has made many Educational Administrators cope with difficulties and problems in administration, management, and running. Moreover, the frequent changes from authorities, and management agencies can also make the Educational Administrators face a lot of pressure in implementing to respond to the change, if they are not prepared in mind and administrative ability to keep up with and adapt to the change. Consequently, the content of change management in schools should focus on:

- Change Management in School's Human Resources

- Change Management in Professional Activities

- Change Management in Learners (mostly in quantity and qualification)

- Change Management in School Culture

\section{Second, determine an appropriate vision}

An obvious vision helps people understand why they are asked to do something. When teachers and employees get what the manager is trying to achieve, then their directions become practically meaningful. To express the vision of change to all teachers, and employees, the manager should compile a brief summary of what is thought to be seen in the school's future so that it is easy to understand, remember, learn by heart, and approve; meanwhile vision speech must be practiced regularly. The manager's vision possibly represents for the entire members of his/ her organization-school; once the manager solves concerns, worry of each person about the future of their unit. However, the issue of rights and the inadequacy of the relationship between obligations and rights, the lack of transparency and fairness in an organization is always barriers to change management in schools.

\section{Third, innovate management method}

The process of school management activity normally takes place in 4 stages: planning, organizing to implement the plan, checking and urging, summarizing and evaluating. During this process, planning plays a decisive role, and the subject of the plan is the activities of individuals, organizations and groups in the school. On 
the other hand, the school's operation plan is mainly based on a certain pattern and obeys the principles and provisions of legal documents, the manager individually only concretizes appropriately so as to be suitable with the situation's features and the conditions of the school. The requirements of the change management method must start from the way of planning and defining human as an object of change management. To develop a change management plan, the manager has to make everyone understand why change must happen by organizing everyone to participate in experiencing the new, which is 'the final target' of a change so that each person can experience it and observe the effect of the new. From there, the manager asks each person to contribute their ideas for how the change should be led for the development of the school. Based on these ideas, the manager makes statistics, categorizes and sets up information for the plan. The plan is a product built close to artificial intelligence because it is connected to the ideas and wills of many people. This is the creating motivation phase with the goal: the motive power to change must be created before change happens. The plan is a relationship among individuals, and between individuals and the community so that they can participate in the process of checking and verifying the results.

\section{Conclusion}

Modern education always promotes individual factors, creates conditions for learners to reveal their hidden abilities and identify themselves in the community and society. Under the impact of Industry 4.0, lower secondary education today not only simply ensures students a basic general education, the minimum necessary knowledge of technology and career guidance to continue their education in high schools or vocational training programs, but also completely changes their learning goals and new skills that need to be acquired in the 4.0 industrial revolution era. In order to gain all the things which have been said above, our attention and focus on change management in secondary schools in Vietnam nowadays are meaningful both in theory and practice when Vietnam is integrating into regions and the world. This study was carried out to analyze and clarify the basic contents related to the change management process in schools and the role of principals in change management at secondary schools in Vietnam currently, as evidenced by the teaching activities at Ly Thanh Tong junior high school, District 8, Ho Chi Minh City. The limitation of this study is that it has not shown and clarified the factors affecting the process of change management in schools and the role of the principals in change management at secondary schools in Vietnam.

\section{REFERENCES}

1. Beare, H. and Slaughter, R. (1993). Education for the Twenty-First Century, London: Routledge. 
2. Final report 2020-2021 of Ly Thanh Tong secondary school, District 8, Ho Chi Minh City

3. Davies, B and Ellison, L. (1997). School leadership in the 21st century - a competency and knowledge approach, London and New York.

4. Le Phuoc Minh et al (2013). Leadership and change management in high schools (Theme 4-Training materials for high school administrators). Pedagogical University Publishing House

5. Dang Xuan Hai (2006), Applying Change management theory in teaching method innovation in schools in the current period. Education Magazine Ministry of Education and Training No. January 2005...

6. Howard Gardner (2014). Changing Minds: The Art and Science of Changing Our Own and Other Peoples Minds. Social Sciences Publishing House

7. Jain C., Prasad N. (2018). "Quality in Education-Concept, Origin, and Approaches". In: Quality of Secondary Education in India. Springer, Singapore.

8. PTTA (2016). Education Change Management Toolkit 2016. New Zealand.

9. Rock KB Everard, Geoff Morris, Ian Wilson (2004). Effective School Management. P.C.P publishing, London.

10.Jain C., Prasad N. (2018). "Quality in Education-Concept, Origin, and Approaches". In: Quality of Secondary Education in India. Springer, Singapore.

11.PTTA (2016). Education Change Management Toolkit 2016. New Zealand.

12.Rock KB Everard, Geoff Morris, Ian Wilson (2004). Effective School Management. P.C.P publishing, London.

13.Improve principals' change managing capacity, https://vietnam.vvob.org/sites/vietnam/files/nang_cao_nang_luc_quan_ly_su thay doi cua hieu truong. de ho tro tre trong giai doan chuyen tiep $\mathrm{t}$ u mam non len tieu hoc.pdf

14. Assoc. Prof. PhD. Tran Mai Uoc, \& Nguyen Long Giao. (2021). The Adjustment Of Educational Administrators To The Impact Of Industrial Revolution 4.0. Galaxy International Interdisciplinary Research Journal, 9(8), 159-164. Retrieved from https://internationaljournals.co.in/index.php/giirj/article/view/225 